

\title{
Carencia alimentaria, cadenas productivas y políticas públicas para el sector agrícola en México
}

\author{
Luis Kato Maldonado y Guadalupe Huerta Moreno
}

UNIVERSIDAD AUTÓNOMA DE CIUDAD JUÁREZ

PUBLICACIÓN AFILIADA A LA

RED IBEROAMERICANA DE ESTUDIOS DEL DESARROLLO 


\title{
UNIVERSIDAD AUTÓNOMA DE CIUDAD JUÁREZ
}

\author{
PUBLICACIÓN AFILIADA A LA \\ RED IBEROAMERICANA DE ESTUDIOS DEL DESARROLLO
}

\section{Universidad Autónoma de Ciudad Juárez}

2018-2024

Mtro. Juan Ignacio Camargo Nassar

Rector

Mtro. Daniel Alberto Constandse Cortez

Secretario General

Mtro. Santos Alonso Morales Muñoz

Director del Instituto de Ciencias Sociales y Administración

Mtro. Jesús Meza Vega

Director General de Comunicación Universitaria

Comité de Coordinación de la Red Iberoamericana de Estudios del Desarrollo 2018-2020

Dra. Paulina Sanhueza Martínez (Universidad de la Frontera, Chile)

Coordinadora General

Dr. Ignacio Rodríguez Rodríguez (Universidad de la Frontera, Chile)

Secretario general

Dra. Myrna Limas Hernández

(Universidad Autónoma de Ciudad Juárez, México)

Vocal de Organización

Dr. Pablo Galaso Reca (Universidad de la República, Uruguay)

Vocal de Organización

Dr. Luis Enrique Gutiérrez Casas

Director y editor de Cuadernos de Trabajo

Estudios Regionales en Economía, Población y Desarrollo

Comité editorial

Sección internacional Dra. Sofía Boza Martínez

(Universidad de Chile, Chile)

Dra. Olga Biosca Artiñano

(Glasgow Caledonian University, Reino Unido)

Dra. Ángeles Sánchez Díez

(Universidad Autónoma de Madrid, España)

Dr. Thomas Fullerton Mankin

(University of Texas at E1 Paso, Estados Unidos)

Dr. Adrián Rodríguez Miranda

(Universidad de la República, Uruguay)

Dra. Ikuho Kochi

(Kanazawa University, Japón)

Dr. Pablo Galaso Reca

(Universidad de la República, Uruguay)

Sección local

(Universidad Autónoma de Ciudad Juárez)

Dra. Myrna Limas Hernández

Dra. Rosa María García Almada

Dr. Raúl Alberto Ponce Rodríguez

Dr. Isaac Leobardo Sánchez Juárez

Dr. Héctor Alonso Barajas Bustillos

Dr. Juan Carlos Medina Guirado

Mtra. María Del Socorro Velázquez Vargas

Diseño de cubierta Abigail Bautista
Estudios Regionales en Economía, Población

y Desarrollo. Cuadernos de Trabajo de la UACJ

ISSN 2007-3739

Número 67. Enero - Febrero 2022

Carencia alimentaria, cadenas productivas y políticas

públicas para el sector agrícola en México

Luis Kato Maldonado y Guadalupe Huerta Moreno

Universidad Autónoma de Ciudad Juárez

Estudios Regionales en Economía, Población y Desarrollo.

Cuadernos de Trabajo de la UACJ

Año 12, No. 67 enero - febrero 2022, es una publicación bimestral editada por la Universidad Autónoma de Ciudad Juárez a través del Cuerpo Académico de Estudios Regionales en Economía, Población y Desarrollo del Instituto de Ciencias Sociales y Administración. Redacción: Avenida Universidad y H. Colegio Militar, Zona Chamizal s/n., C.P. 32300, Ciudad Juárez, Chihuahua, México.

Teléfonos: (656)688-38-00, ext.3792.Correo electrónico: igtz@uacj.mx. Editor responsable: Luis Enrique Gutiérrez Casas. Reserva de derechos al uso exclusivo: edición impresa, ISSN 2007-3739., edición digital, No. de reserva 04-2019-050218151500. Impresa por Studio Los Dorados, calle Del Campanario, número 820-2, Santa Cecilia, C.P. 32350, Cd. Juárez, Chihuahua. Distribuidor: Subdirección de Gestión de Proyecto y Marketing Editorial. Ave. Plutarco Elías Calles 1210, Foviste Chamizal, C.P. 32310, Ciudad Juárez, Chihuahua. Este número se terminó de imprimir el 15 de diciembre 2021 con un tiraje de 120 ejemplares.

Los ensayos publicados son responsabilidad exclusiva de sus autores.

Se autoriza la reproducción total o parcial bajo condición de citar la fuente.

\section{Registrada en: EBSCO RePEC latindex \\ UAC] 侧 Revistas Electrónicas ๑ Dialnet}

Publicación afiliada a la Red Iberoamericana de Estudios del Desarrollo

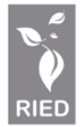

Universidad Autónoma de Ciudad Juárez

Ave Plutarco Elías Calles 1210

Foviste Chamizal, C.P. 32310

Ciudad Juárez, Chihuahua, México

www.uacj.mx

(C) Universid ad Autónoma de Ciudad Juárez 


\title{
Carencia alimentaria, cadenas productivas y políticas públicas para el sector agrícola en México
}

\author{
Luis Kato Maldonado * y Guadalupe Huerta Moreno
}

\begin{abstract}
Resumen
El objetivo de este trabajo es presentar un análisis respecto de los principales problemas del sector agrícola en México en dos periodos clave. Uno que va de 1940 a 1983 y otro que cubre los años de 1984 a 2017. Esta periodización permite ubicar los cambios más relevantes entre lo que fue la estrategia de autosuficiencia alimentaria y la crisis actual de la agricultura mexicana, la cual se caracterizada por dos fenómenos. Por una parte, el predominio de grades empresas articuladas a la comercialización internacional de productos de exportación y, por otra, la existencia de un amplio número de productores rurales viendo en condiciones de precariedad y cuya sobrevivencia depende del mercado interno. El análisis presentado permite proponer los elementos que una política pública agrícola debería incluir con el objetivo de enfrentar la problemática en el campo y avanzar hacia la soberanía alimentaria.
\end{abstract}

Palabras clave: Políticas públicas, soberanía alimentaria, seguridad alimentaria, sector agrícola.

\section{Food deficit, production chains and public policies for the agricultural sector in Mexico}

\begin{abstract}
The aim of this paper is to present an analysis regarding the main issues in the agricultural sector in Mexico in two key periods. One that goes from 1940 to 1983 and another that covers the years 1984 to 2017. This periodization allows locating the most relevant changes between what was the food self-sufficiency strategy and the current crisis in Mexican agriculture. which is characterized by two important phenomena. On the one hand, the predominance of large companies linked to the international marketing of export products and, on the other hand, the existence of a significant number of rural producers living in precarious conditions and whose survival depends on the domestic market. The analysis presented makes it possible to propose the key elements that a public policy for the agricultural sector should include in order to face the problems of this sector and move towards food sovereignty.
\end{abstract}

Keywords: Public policies; Food sovereignty, food security, agricultural sector. JEL: $013, N 56, Q 18$.

Recibido en: julio de 2021.

Aprobado en: octubre de 2021.

\footnotetext{
* Profesor del Departamento de Economía de la Universidad Autónoma Metropolitana -Azcapotzalco (México). Integrante del Cuerpo Académico de Sociedad y Acumulación Capitalista. Correo electrónico. luiskatomaldonado@azc.uam.mx. ORCID: 0000-0003-1257-9382.

** Profesora del Departamento de Administración de la Universidad Autónoma Metropolitana -Azcapotzalco (México). Integrante del Cuerpo Académico de Sociedad y Acumulación Capitalista. Correo electrónico: mghm@azc.uam.mx. ORCID: 0000-0003-0854-3686.
} 


\section{○ 1. Introducción.}

La crisis económica mundial actual, catapultada por la pandemia desatada por brote del SARS 2COVID 19, es la más grave desde los años treinta del siglo XX y amenaza con aumentar el hambre en el mundo. En ese contexto, y frente a las ajustes presupuestales sectoriales impuestos por la emergencia sanitaria, uno de los problemas más serios que enfrenta el país es la condición estructural de la producción agrícola, hecho que se agrava por la falta de políticas públicas integradoras que mejoren las condiciones de producción, el acceso a financiamiento suficiente y oportuno, el apoyo técnico y la construcción acelerada de las obras de infraestructura agrícola necesarias para aumentar de la producción en el campo.

Actualmente, la demanda social de alimentos se satisface por un conjunto de productores que recurren a métodos técnicos relativamente estándares —en función de los procesos biológicos que determinan la reproducción, el crecimiento y desarrollo de las plantas y animales — o que utilizan diferentes recursos naturales y técnicos (agua, tierra y riego), lo que incide de manera desigual en la productividad del trabajo agrícola. Por lo tanto, la productividad global en el sector agrícola se expresa en rendimientos por hectárea diferenciados en función de los insumos utilizados, la tecnología aplicada y la capacidad suelo para incorporar a su sustrato nutrientes que en la forma de fertilizantes permiten a las plantas asimilar y soportar la utilización de cantidades enormes de pesticidas, fungicidas y herbicidas para controlar plagas. ${ }^{1}$

Ese patrón tecnológico y el diseño inadecuado de políticas públicas para el sector agrícola no permiten concretar en los hechos los conceptos de soberanía y seguridad alimentarias. El primero, entendido como "el derecho de los pueblos a definir sus propias políticas y estrategias sustentables de producción, distribución y consumo de alimentos para toda la población, con base en la pequeña y mediana producción, respetando su cultura y la diversidad de los modos campesinos, pesqueros e indígenas de producción agropecuaria, de comercialización y de gestión de los espacios rurales, en los cuales la mujer desempeña un papel fundamental" (Foro Mundial sobre Soberanía Alimentaria, 2001). El segundo, se refiere a factores físicos, económicos y sociales, y se vincula a un estatus nutricional adquirido en función del nivel de ingreso y, por lo tanto, del poder adquisitivo. Aunque éste es central para el acceso y la calidad de los alimentos, el concepto también incorpora las pautas

\footnotetext{
${ }^{1}$ Esto es lo que denominamos fertilidad de los recursos naturales.
} 
del consumo de las poblaciones y las familias en la búsqueda de una vida sana y en condiciones reproducción social con bienestar biológico. ${ }^{2}$

En contraposición a la seguridad alimentaria está la carencia de acceso a la alimentación, y que de acuerdo con el Consejo Nacional para la Evaluación de la Política Social (CONEVAL) se refiere a aquella situación en la que “... una persona presenta un grado de inseguridad alimentaria moderado o severo..." (CONEVAL, 2014). Es decir, existe población con hambre que no ha podido hacer alguna de las tres comidas diarias o que no está ingiriendo la dieta necesaria para preservar su salud biológica (Bartra, 2007). De 2008 a 2018 el total de la población con carencia alimentaria -leve, moderada y severa- se redujo de 51.5 millones de personas a 49.7 millones, pero las cifras para la inseguridad alimentaria moderada y severa crecieron. El primer caso pasó de 14.3 millones de personas a 15.1 millones y el segundo de 10 millones a 10.4 millones de personas (CONEVAL, 2018a). Además, con el deterioro de los ingresos y el aumento de precios de los alimentos asociados a los efectos económicos de la pandemia del Sars CoV2 la carencia de acceso a una alimentación de calidad y nutritiva aumentó del $22.2 \%$ al 22.5\%, es decir, pasó de 27.5 a 28.6 millones de habitantes entre 2018 y 2020 (CONEVAL, 2020).

Considerando ese contexto, planteamos la hipótesis de que los programas de desarrollo agrícola hasta ahora implementados no resuelven las problemáticas del sector y han contribuido a perpetuar las desigualdades en el campo, pues al no considerar en sus grandes definiciones las asimetrías existentes entre los distintos productores, los procesos de especulación en los mercados de alimentos y los espacios de poder involucrados se debilitan los esfuerzos institucionales para mejorar las condiciones de la producción de alimentos en el país. De ahí que, tales aspectos deben ser el punto de partida para diseñar políticas públicas capaces de promover el desarrollo agrícola, aumentar la producción de alimentos y mejorar el bienestar de los productores del campo.

Después de esta introducción, el artículo se divide en cuatro apartados. En el primero, se hace una revisión de las condiciones en que se encuentra el campo en México y se explica la problemática el sector agropecuario con relación a la conformación del mercado capitalista para la agricultura en México. En el segundo, se analiza lo que denominamos la inviabilidad del modelo productivista para el sector agropecuario. En el tercero, se proponen los lineamientos generales que deben incluirse en la construcción de la política pública para el sector agrícola que en una perspectiva de mediano y

\footnotetext{
${ }^{2}$ En la Cumbre Mundial de la Alimentación desarrollada de 1996, la Organización de las Naciones Unidas para la Alimentación y la Agricultura (FAO) definió a la seguridad alimentaria como la situación en la que: “... todas las personas tienen en todo momento acceso físico, social y económico a los alimentos suficientes, inocuos y nutritivos que satisfagan sus necesidades energéticas diarias y preferencias alimentarias para llevar una vida sana y activa" (FAO, 1996).
} 
largo plazo sea sustentable y haga realidad la seguridad y la soberanía alimentarias. En el cuarto, se exponen las conclusiones del trabajo.

\section{La desigualdad estructural en el sector agropecuario.}

La propiedad social en el país, propiedad ejidal y comunal, alcanza el 50.8\% del territorio nacional y está compuesta por 29709 ejidos y 2393 comunidades con una superficie en conjunto de 100 millones de hectáreas (RAN, 2017). La superficie total agrícola en 2017 contabilizaba 32406237 hectáreas, divididas en 6810762 de riego y 25595475 de temporal, correspondiendo a la primera el $21 \%$ y a la segunda el $78 \%$ del total de superficie destinada a la producción agrícola. Para la primera el agua no es un problema y los métodos de riego más utilizados son por gravedad o rodado, seguido del goteo y la aspersión, en tanto que el tipo de semilla más utilizado en los cultivos era la semilla criolla $(77.5 \%)$, seguida de la mejorada $(25.7 \%)$, certificada $(10.1 \%)$ y la transgénica $(0.4 \%)$. La producción de riego se acompaña de la utilización creciente de fertilizantes, herbicidas, insecticidas, abonos naturales, control biológico de plagas etcétera (INEGI, 2017). En el caso de la agricultura de temporal los niveles de riesgo por pérdida de cosechas son significativamente altos, pues el cambio climático está incidiendo cada vez más en la perdida de cosechas por sequías, heladas, precipitación inadecuada de lluvias y/o contaminación de mantos acuíferos que reducen la cantidad y la calidad del agua subterránea para las siembras.

La población rural en México ha cambiado cuantitativa y cualitativamente a largo de las décadas. En términos porcentuales en 1960 representaba 49.3\% del total de la población, en 1990 ese porcentaje había bajado a $28.6 \%$, en el 2000 era el $25.3 \%$ y en 2018 se ubicaba en $19.8 \%$. Un cambio cualitativo relevante es que el aumento de la migración de jóvenes de las áreas rurales a los grandes centros urbanos del país o a otros países, principalmente a Estados Unidos, para emplearse en la agricultura internacional, la construcción o el sector servicios ha producido un fenómeno de descampesinización seguido de un papel más protagónico de las mujeres como propietarias de la tierra. Así, mientras en 2012 el porcentaje de productoras en el campo era del 13.5\% de total, para 2017 esa cifra se había incrementado a 14.5\% del total, siendo “...un millón 877 mil mujeres dueñas de la tierra, que se distribuyen en 701 mil ejidatarias, 201 mil comuneras, 656 mil posesionarias y 318 mil propietarias privadas" (FAO, 2018: 5).

Sin embargo, las mujeres son las que enfrentan desventajas significativas frente a los hombres. Del total de mujeres y hombres ocupados en el sector agropecuario en 2012, el 65.6\% de mujeres no recibía remuneración alguna frente al 45.9\% de hombres y en 2017 el porcentaje de mujeres no 
remuneradas había aumentado a $71.2 \%$, en tanto que los hombres no remunerados fueron el $44.1 \%$ ese mismo año. A pesar de que en términos globales las mujeres tienen una mayor participación en actividades agropecuarias sus remuneraciones han empeorado (INEGI, 2012; INEGI, 2017).

Además, son las comunidades rurales donde se expresan los mayores niveles de pobreza, rezagos y carencia sociales. De 2008 a 2018 los indicadores de pobreza y pobreza extrema en el medio rural pasaron de16.2 millones de personas a 17 millones y de 7 millones de personas 5 millones, respectivamente. Periodo en el que se produjo una ligera mejoría en el indicador de carencia por acceso a la alimentación, que en el sector rural pasó de 8.4 millones de personas a 7.9 millones (CONEVAL, 2018b; Cámara de Diputados, 2019).

Por su parte, la producción agrícola en 2018 de productos anuales y perennes por orden de importancia fueron, para los primeros, maíz blanco (53\%), maíz amarillo (18\%), trigo (7.4\%), jitomate rojo (7\%), chile $(4.6 \%)$, frijol (3\%), cebolla $(2.4 \%)$ calabaza $(1.7 \%)$, soya $(0.6 \%)$ y arroz (0.3\%); y, para los segundos, caña de azúcar (85.2\%), naranja (4.3\%), plátano (3.3\%), mango (2.5\%), limón ( $1.6 \%)$, café $(1.2 \%)$, uva (0.4\%), manzana $(0.5 \%)$, fresa $(0.3 \%)$ y cacao $(0.06 \%)$ (INEGI, 2017$)$. Cabe señalar que el $50 \%$ de los cultivos cosechados se utiliza como materia prima, es decir, su demanda inicial no es para consumo humano y su potencial económico se deriva de que forman parte de los insumos de productos finales articulados a las cadenas de valor de productos agroindustriales comercializados internacionalmente. Consecuentemente, el aumento de la producción agrícola y los saldos positivos la balanza agropecuaria y agroindustrial, principalmente desde 2015, no representan avances significativos en el logro de la soberanía y la seguridad alimentarias (Gráfica 1).

\section{Producción agrícola anual y saldos agropecuario y agroindustrial}

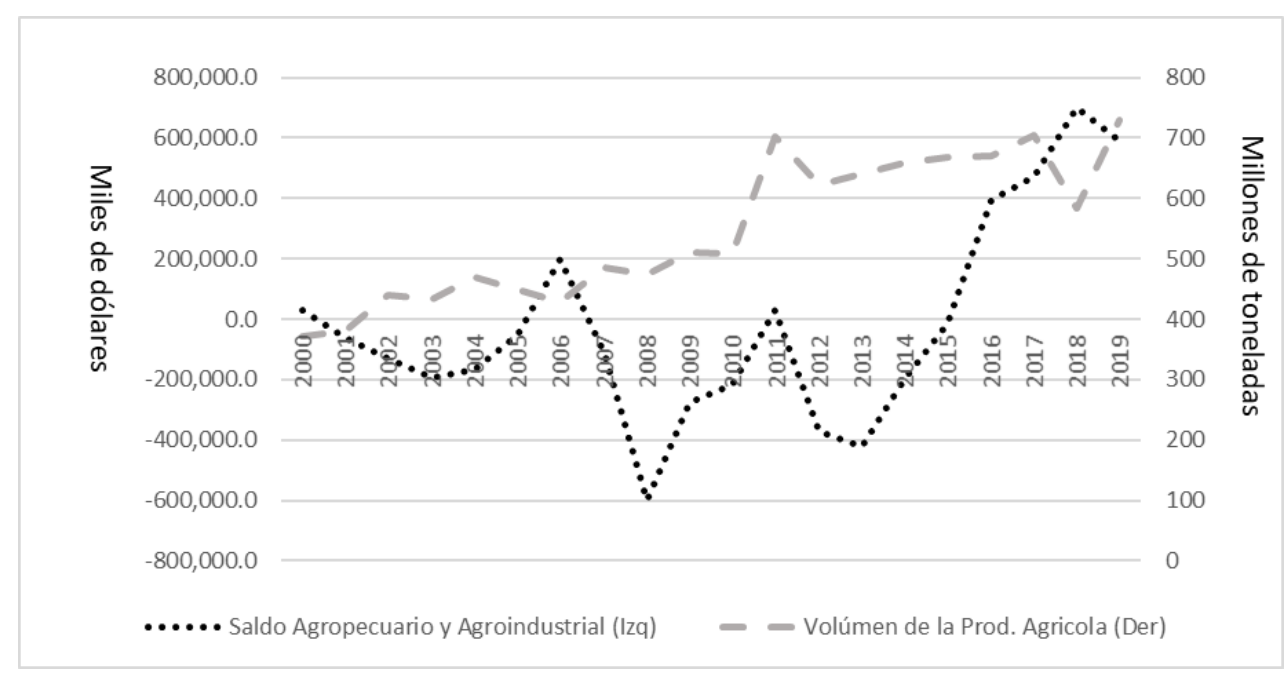

Fuente. Elaboración propia con datos del SIE, Banco de México y SAGARPA (SIAP), Datos abiertos. 


\subsection{La conformación del mercado capitalista para la agricultura en México.}

Un panorama preciso del estado del campo en México se deriva de la Encuesta Nacional Agropecuaria de 2017 del INEGI, en la misma se menciona que la superficie total agrícola de riego y temporal era de 110.25 millones de hectáreas, de la cuales 32.40 millones integran la superficie agrícola de las diferentes unidades productivas en el campo. En esa área productiva existe un patrón dual de crecimiento agropecuario caracterizado por la heterogeneidad de los productores. En un lado están los productores ubicados en las 6.81 millones de hectáreas de superficie productiva de riego, con una estructura de mercado oligopólica controlada por grandes empresas transnacionales que concentran la producción de bienes intermedios y de capital, así como los procesos de comercialización lo que les permite abastecer eficientemente a la agroindustria. De otro, coexisten un gran número de productores agrícolas ubicados en 25.59 millones de hectáreas de temporal en regiones con los mayores niveles de ruralidad y marginación (ejidatarios, pequeños propietarios, comuneros, posesionarios), con escalas de producción reducidas y sin capacidad para acceder a insumos o bienes de capital, lo que resulta en condiciones productivas precarias que les impiden aumentar su productividad. Además, son los productores agrícolas más afectados por la pérdida de cosechas derivadas del cambio climático.

La existencia de una estructura productiva altamente diferenciada provoca que a nivel agregado la productividad total agropecuaria se explique fundamentalmente por las actividades de grandes productores con terrenos competitivos integrados en distritos de riego, que no tiene problemas ni para acceder a créditos, ni a insumos de calidad y tecnología agrícola de punta que les garantizan una alta productividad, crecimiento y participación en los mercados internacionales. En tanto que los agricultores cuyo espacio de reproducción está en los mercados locales y regionales enfrentan restricciones severas. Sus terrenos son de hasta cinco hectáreas (minifundios) que pueden estar separadas, y su acceso a medios de producción tecnificados, a inversiones y recursos crediticios son bajos por lo que la contracción del mercado interno, derivada de un crecimiento económico del $2.6 \%$ en promedio entre 1990 y 2018, los ha dejado en una situación de sobrevivencia.

La modernización excluyente y el patrón de desarrollo diferenciado existente en el sector agropecuario en México ha contribuido no solo para que el incremento de la productividad del trabajador agrícola se sustente en el uso intensivo y conjugado de infraestructura e insumos especializados, tales como semillas mejoradas, herbicidas, pesticidas y maquinaria agrícola especializada, sino también para que el campo mexicano en su conjunto presente problemas de reproducción asociados a la falta de tecnología apropiada, la reducida escala de inversión en infraestructura agrícola y la carencia de políticas integradoras para lograr una distribución equitativa entre todos los productores del campo de insumos y apoyos financieros. Lo que ha llevado a la 
contracción del ingreso de los campesinos, la caída en el ritmo de crecimiento del empleo rural y la quiebra de los productores menos tecnificados, causas fundamentales de la carencia alimentaria en nuestro país (Kay, 1995; Leyva, 2012; INEGI,2017).

Ese modelo de desarrollo modernizador excluyente en el sector agrícola se desplegó en dos etapas: una de 1940-1983 y la otra de 1984-2017. Ambas se diferencian por las características, por una parte, de los esquemas de inversión y programas de apoyo público en las industrias abastecedoras de insumos especializados y, por otra, por la conformación de mercados de producción agrícola capitalista y la inserción de los grandes productores a las cadenas agroalimentarias globales (Herrera, 2013).

La primera etapa se consolidó a partir del esquema de propiedad social heredada de las demandas del campesinado después de la Revolución y de la dinámica productiva de los ejidos, aquí la intervención pública se concentró en:

a) Impulsar un mercado nacional de productos agropecuarios;

b) Inducir un proceso de capitalización acelerada en el sector agrícola tendiente a lograr la autosuficiencia alimentaria en productos básicos;

c) Promover el desarrollo nuevas agroindustrias que deberían orientarse al mercado interno y, al mismo tiempo, estimular la producción nacional de bienes de capital e insumos para la agricultura;

d) Apoyar la producción agrícola con el suministro coordinado de insumos tales como semillas hibridas, insecticidas, fertilizantes, abonos y maquinaria agrícola;

e) Desarrollar un mercado crediticio estable y de largo plazo para el sector agrícola, y;

f) Estimular la exportación agrícola en la medida en que se sustituyeran cultivos conforme variaran los precios internacionales.

El Estado impulsó programas de inversión dirigidos, en primer lugar, a canalizar cantidades crecientes de recursos públicos para incrementar los rendimientos de producción por hectárea cosechada a partir de la construcción de obras de irrigación, caminos e infraestructura de almacenamiento. En segundo lugar, se dio a la tarea de impulsar el desarrollo de un mercado de capitales ad-hoc para el sector agrícola con la creación y expansión de empresas paraestatales destinadas a producir insumos intermedios y de capital para la agricultura. Entonces, la articulación entre la agricultura y el sector industrial permitiría que en el largo plazo no se produjera una relación de precios relativos adversa para el segundo que impidiera su adecuada capitalización (Kato, 2005). En ese sentido, fue fundamental que las empresas paraestatales apoyaran el desarrollo de las industrias 
productoras de insumos intermedios y de capital altamente especializadas -industrias de pesticidas, fertilizantes, maquinaria agrícola y semillas mejoradas- necesarias para endogeneizar la base de los incrementos de la productividad agrícola.

Con el avance del proceso de sustitución de importaciones, la producción de los principales insumos agrícolas se canalizó a satisfacer la demanda del polo capitalista avanzado de la agricultura mexicana, lo que impidió que la composición de la oferta de dichos insumos se adecuara a las necesidades reales de la mayoría de los productores agrícolas. De ahí que, las demandas potenciales no se pudieron satisfacer adecuadamente y, con ello, el desarrollo de ese segmento del sector industrial encontró límites estructurales, tanto por el lado de oferta potencial como de la demanda efectiva, los cuales se subsanaron gracias a erogaciones del Estado, sacrificios fiscales y bajos intereses en los créditos destinados a apoyar la compra de insumos y bienes de capital. Sin embargo, la estrategia para consolidar a las empresas paraestatales cuyas actividades deberían apuntalar el fortalecimiento del sector agrícola ${ }^{3}$ fracasó debido a que:

i. Los precios de los insumos y bienes de capital destinados al sector agrícola se fijaban por debajo de los precios internacionales, pues la política estatal consistía en el otorgamiento de subsidios (directos e indirectos) para alentar el desarrollo del campo mexicano. Ante la inexistencia de un mercado que impusiera las normas de calidad para sobrevivir en un entorno competitivo, ello provocó la descapitalización paulatina de las empresas que dependían del subsidio del Estado.

ii. La planta industrial que producía insumos y bienes de capital para el campo estaba centralizada en pocas empresas altamente especializadas que controlaban la oferta y condicionaban, mediante distintos medios, la demanda agrícola de los mismos. En algunos casos su oferta precedió a la demanda efectiva (fertilizantes) y en otros presentó rezagos (maquinaria agrícola y plaguicidas) en relación con los requerimientos de sector agrícola.

iii. La comercialización de dichos insumos y bienes se realizaba a través de la banca de fomento, por lo tanto, dependía de la solvencia de pago de los productores y de los cajones de crédito definidos en función de la política estatal en turno (Kato, 2005).

En términos de ventajas competitivas, lo anterior se traducía en la imposibilidad de desarrollar un mercado financiero profundo para la agricultura, que no existiera una oferta nacional eficiente de insumos intermedios y bienes de capital y que los subsidios estatales no beneficiaban al productor

\footnotetext{
${ }^{3}$ Incluido al sector agropecuario.
} 
directo. Por lo que la soberanía alimentaria alcanzada en esta etapa estaba sustentada sobre bases muy endebles.

A principios de los ochenta la erosión tanto de la política de desarrollo agrícola como de la expansión de las industrias productoras de bienes intermedios y de capital para el sector estaba acompañada del estancamiento de la productividad de los productores agropecuarios. En paralelo, el viraje en el modelo económico hacia las políticas del lado de la oferta y la imposición de diversas reformas estructurales marcaron el cambio de estrategia de desarrollo del país y la apertura de la economía nacional. En ese nuevo contexto se inserta la segunda etapa del desarrollo modernizador excluyente (1984-2018) del sector agrícola, y cuyos rasgos son:

a) La liberalización comercial de la agricultura a fin de contribuir mediante el abasto externo al abatimiento de la inflación;

b) Hacer de la competencia externa la variable clave para elevar los niveles de eficiencia de los productores nacionales;

c) Privatizar las empresas paraestatales productoras de insumos intermedios y bienes de capital especializados para la agricultura y acelerar su libre importación;

d) Favorecer la especialización del sector exportador para aprovechar las ventajas comparativas en el sector agropecuario y así financiar las importaciones de productos agrícolas que no se pudieran producir internamente ${ }^{4}$;

e) La implementación de políticas focalizadas a grupos y regiones prioritarias para eliminar los factores críticos que impidieran el logro de la reconversión y la eficiencia productivas del sector agrícola;

f) Apoyar la consolidación de los sectores agroalimentarios rentables y orientarlos al mercado externo (Kato, 2005).

Un antecedente relevante para el sector agrícola mexicano previo a la integración del país al Tratado de Libre Comercio de América del Norte (NAFTA, por sus siglas en inglés), es la reforma al Artículo 27 constitucional de 1992 que modificó el derecho agrario, redefiniendo las formas de tenencia de la tierra mediante el otorgamiento de títulos de propiedad individual en terrenos de propiedad colectiva y/o comunal. Esta reforma pretendía trasformar el campo mexicano y acelerar su reconversión capitalista con la eliminación de los minifundios, la liberalización de tierras para su comercio y la capitalización empresarial del campo con formas mercantiles altamente diferenciadas

\footnotetext{
${ }^{4}$ Lo cual se acompañó de la integración de las cadenas agroalimentarias y de pesca.
} 
de la propiedad social comunal. El punto clave aquí era que para fortalecer la apertura comercial había que crear un mercado de tierras agrícolas privado capaz de articularse a la nueva dinámica capitalista de los negocios agrarios insertos en las cadenas de valor de productos agroindustriales en los mercados internacionales (Bouquet,1996; Pérez y Mckinlay, 2015; Torres-Mazuera, 2019). ${ }^{5}$

En el marco del discurso de la gobernanza, donde aparentemente todos los actores involucrados en la reorganización de las tierras destinadas a la producción agrícola estarían incluidos, las estrategias de medición, registro y otorgamiento de títulos brindaban la posibilidad de que la tierra fuera sustraída de la producción por los especuladores que la consideran una inversión o un activo que puede enajenarse. En realidad, la reforma se orientaba a que los agricultores más pobres fueran inducidos a vender la tierra, particularmente, si estaban endeudados y ya no podían liquidar sus obligaciones crediticias debido a una mala cosecha u otras circunstancias adversas (Deininger 2003; Conroyd, et al, 2014; Henderson, et. al, 2014; Giraldo, 2015; OECD, 2018).

En esta segunda etapa y en el contexto de la apertura económica, los técnicos de la estructura institucional creada -AGROASEMEX, ASERCA, MASAGRO, PROCAMPO, PROMOAGRO ${ }^{6}$, etcétera - no definieron con precisión las cadenas productivas y los canales de comercialización (local, nacional e internacional) que darían un impulso renovado al campo mexicano, es decir, no hicieron un diagnóstico correcto de los procesos de producción integrados a partir de las escalas de producción y la productividad con que operan los distintos tamaños de productores en función de sus diferentes mercados. Consecuentemente, la reforma de 1992 no tuvo el impacto esperado por sus promotores y el minifundio sigue siendo la forma de propiedad de la tierra rural predominante. Esto muestra que la titulación individual importa menos a los campesinos pobres que la seguridad de la tenencia porque la tierra sirve como una red de seguridad social que les proporciona los medios básicos de subsistencia en que desarrollan su vida (Gallardo, 2003; De Schutter, 2010; FAO, 2018).

La estrategia para la conversión del campesino a empresario se insertó, más que en una política de desarrollo, en una tendencia hacia la exclusión de toda forma de producción que no opere bajo los criterios de costo-beneficio, dejando de lado que el patrón de acumulación que se estaba imponiendo requiere de cierta autonomía por parte de la fuerza de trabajo para allegarse de medios de subsistencia. Esto en la medida en que, por un lado, las tasas de crecimiento de la economía no

\footnotetext{
${ }^{5}$ Un actor fundamental de la reforma fue el Consejo Nacional Agropecuario (CNA) que venía buscando esa reforma desde tiempo atrás.

${ }^{6}$ Aseguradora Mexicana, Institución Nacional de Seguros Agropecuarios; Apoyos y Servicios a la Comercialización Agropecuaria; Fondo Nacional de Garantías de los Sectores Agropecuario, Forestal, Pesquero y Rural; Programa de Apoyos Directos al Campo (vigente hasta 2013); Programa de Promoción Comercial y Fomento a las Exportaciones de Productos Agrícolas y Pesqueros Mexicanos.
} 
garantizan la plena ocupación de la fuerza de trabajo y, por otra, que los niveles de salario son insuficientes para cubrir las necesidades de reproducción de la fuerza de trabajo.

Muchas de las consideraciones alrededor de las dos principales estrategias de política agrícola se basaban en que el sector dependería íntegramente para elevar su productividad en el largo plazo de las grandes empresas (nacionales o transnacionales) productoras de insumos intermedios y de capital. Asimismo, se suponía que los patrones de especialización de los productores agrícolas se consolidarían en función de los mercados nacional e internacional, y que una mayor seguridad en la tenencia de la tierra mejoría los incentivos para invertir, además el aumento de la demanda de capital y la utilización de insumos intermedios más eficientes incrementaría también la productividad de los productores con tierras comunales y colectivas.

No obstante, el modelo intensivo de producción agrícola en sus dos etapas (interiorización tecnológica de la producción de insumos intermedios y de capital y de articulación a cadenas de valor agropecuaria con base en una mayor productividad) generaron la pérdida de soberanía alimentaria y profundizaron el fenómeno de la carencia alimentaria (pobreza) en muchas regiones del país.

\section{La inviabilidad del modelo productivista para el sector agropecuario.}

El cambio tecnológico en el sector agrícola se ha acelerado con el uso intensivo de las técnicas biotecnológicas basadas en la ingeniería genética. Al mismo tiempo se ha producido un fenómeno de alta concentración en las industrias de pesticidas y maquinaria agrícola (Williams, 2007; Lavarello y Goldstein, 2011; ETC Group, 2013). Aunque el mayor aporte de las nuevas tecnologías al sector agrícola es la producción de semillas modificadas genéticamente que, dada su gran capacidad de adaptación a diversas condiciones de producción, han demostrado un alto potencial para elevar los rendimientos por hectárea (Aboites y Félix, 2011). Por lo tanto, parecería que utilizar semillas transgénicas es la solución para incrementar la oferta agrícola nacional y con ello paliar la crisis alimentaría que enfrenta el país. Sin embargo, esas semillas son producidas por grandes transnacionales cuyas políticas de desarrollo, metas de rentabilidad, expansión y amortización de sus gastos en investigación no contemplan estrategias para su adaptación al entorno biótico y ecológico de cada país, ni consideran el marco institucional de la propiedad de la tierra, el cual determina la reproducción social de la mayor parte de la población campesina. Lo que sí ha sucedido es que esas innovaciones han modificado radicalmente no solo formas de producir en los sectores más rentables de los commodities agrícolas - maíz, arroz, café, sorgo, trigo, soya entre otros- sino que sus 
mecanismos de comercialización están cada vez más inmersos en fenómenos de especiación que resultan en oleadas de especulación y volatilidad de los precios de los productos agrícolas que se negocian internacionalmente.

\subsection{El control oligopólico de la producción de semillas a nivel mundial.}

En años recientes las llamadas "grandes seis" agbiotech companies (Dow, DuPont, Bayer, Monsanto, Syngenta y BASF) se han ido reacomodando en el mercado internacional. En febrero de 2016, Syngenta acordó ser comprada por la Corporación Química Nacional de China (ChemChina) por 43 mil millones de dólares. En septiembre de ese año, Monsanto anunció una propuesta de fusión con Bayer por 66.000 millones de dólares. Esas megafusiones han resultado en la consolidación de cuatro compañías de biotecnología extremadamente grandes: Dow / Dupont, ChemChina / Syngenta, Monsanto / Bayer y BASF (Bratspies, 2017). Las mismas que han impulsado reformas internacionales para hacerse del control de los derechos de propiedad intelectual de semillas a nivel mundial y con ello beneficiar a los países desarrollados y sus empresas. Situación que para países como el nuestro significa el retroceso del derecho de los campesinos a las semillas.

Cuando una empresa invierte en la investigación orientada a la selección y mejoramiento de semillas busca obtener a cambio un derecho de propiedad intelectual -patente o certificado de obtención vegetal (COV)- sobre las mismas. Inicialmente, los COV estaban reglamentados por el Convenio de la Unión Internacional para la Protección de las Obtenciones Vegetales (UPOV) de 1961 y concedían a los titulares de derechos poderes inferiores a los de las patentes. Los agricultores tenían que comprar las semillas protegidas por un COV, pero después de la cosecha eran libres de mantener una parte con el fin de multiplicarlas y de forma gratuita utilizarlas en nuevas siembras. La revisión en 1991 del Convenio UPOV endureció el sistema de propiedad intelectual, pudiendo cada país optar por conservar o no esa libertad para los campesinos (Correa, 2015; Erard et al, 2017). Actualmente, las multinacionales pueden registrar patentes de rasgos nativos, que les otorgan "derechos de obtenedor", es decir, adquieren el control sobre una variedad o conjunto de plantas -materias vivascon determinado genotipo o conjunto de genotipos. ${ }^{7}$ Una vez asignados los títulos de propiedad intelectual ${ }^{8}$ se pueden exigir derechos de licencia sobre el uso de todas las plantas que posean determinadas características, incluso de aquellas plantas que se han cultivado por los campesinos desde generaciones.

\footnotetext{
${ }^{7}$ La RAE (1992) define genotipo como: conjunto de genes existentes en cada uno de los núcleos celulares de los individuos pertenecientes a una determinada especie vegetal o animal.

${ }^{8}$ Lo que no es otra cosa que la privatización de la naturaleza.
} 
En esos términos, los cambios técnicos y jurídicos auspiciados globalmente por las grandes multinacionales biotecnológicas impiden a los campesinos pobres el acceso y la utilización de un creciente numero de variedades de semillas tradicionales que han sido registradas con una patente sobre un rasgo nativo. Esto refuerza los riesgos de biopiratería y expone a los campesinos al peligro de ser procesados si cultivan sin saberlo plantas que posean una característica patentada y/o a enfrentar obligaciones respecto del pago de regalías (Erard et al, 2017). Así las empresas biotecnológicas que controlan las semillas mejoradas genéticamente ejercen un poder real sobre los alimentos en el mundo.

Tal complejidad obliga a un mejor diseño de las políticas y las acciones pública para el sector agrícola, porque los programas y las intervenciones públicas deben generar efectos dinámicos que beneficien a todos los productores del campo, en particular a los campesinos con mayores carencias, pues los altos precios de los insumos -maquinaria y equipo, precio de combustibles, semillas y/o fertilizantes- y la falta de acceso al crédito en condiciones preferenciales son dos de las principales razones por las que los pequeños agricultores no pueden superar el nivel de la agricultura de subsistencia (INEGI, 2019).

Además, cuando han pasado al monocultivo, que implica una menor resistencia ante el cambio climático, aunque pueden tener ingresos más elevados en ciertas temporadas, los mismos también pueden ser menos estables de unos años a otros. Ello sin considerar que el aumento de las superficies cultivadas con semillas comerciales reduce la diversidad de los cultivos y degrada la capacidad de la tierra para reconstituir los nutrientes de los que se alimentan las plantas, ya que un número creciente de agricultores cultivan los mismo y utilizan en sus campos las mismas variedades de semillas "mejoradas". Consecuentemente, las semillas de patente comercial pueden ser menos apropiadas para los entornos ecológicos específicos en los que los pequeños agricultores trabajan, y para los que las variedades de semillas tradicionales resultar ser más convenientes.

Esto es importante en la medida en que el surgimiento de una estructura de patentes para el uso de semillas ha provocado la creación de un sistema comercial de semillas paralelo y diferente a aquel en el que los pequeños agricultores tradicionalmente conservan, intercambian y venden semillas, con frecuencia al margen de los cauces oficiales. Este sistema de comercio para ellos es una fuente de independencia y fortaleza frente a amenazas tales como las plagas, las enfermedades o el cambio climático. De ahí que, la investigación privada en el campo de la ingeniería genética de semillas, fundamental en la privatización de la naturaleza y su comercialización con criterios de rentabilidad empresarial, puede intentar satisfacer las necesidades de los agricultores de los países industrializados, pero es incapaz de atender, porque no es rentable y no le interesa, las necesidades específicas de los agricultores pobres de los países en desarrollo (CECCAM, 2008). 
De lo anterior se desprende que los procesos de centralización y concentración de capital observados en los principales eslabones de la cadena de producción agropecuaria internacional, en particular agroquímicos y la producción de semillas, son los determinantes fundamentales del rendimiento y del costo de producción para los diferentes productores $\mathrm{y}$, en gran medida, de la carencia alimentaria que tiene nuestro país. Las razones de ello son:

a) El sector agropecuario es básicamente usuario de innovaciones tecnológicas controladas por los proveedores de insumos y bienes de capital que se encuentran relacionados con productores agrícolas con recursos naturales óptimos para el aprovechamiento de los insumos y bienes de capital de alta tecnología.

b) La productividad de los usuarios de bienes intermedios y de capital de alta tecnología para la agricultura es muy frágil pues depende básicamente de una combinación de insumos que puede ser óptima en un lapso y dejar de serlo por los procesos de innovación que son desarrollados fuera de la esfera de la producción agropecuaria directa.

c) La innovación tecnológica que pueden realizar los productores primarios es principalmente en proceso, es decir, no tienen capacidad de hacer innovaciones en producto pues la base de ese tipo de innovaciones cabe subrayar, se produce fuera de la esfera de la producción agropecuaria (Jaffé, 1993).

Entonces, los efectos de la dependencia tecnológica respecto de las grandes empresas productoras de insumos intermedios y bienes de capital en la lucha por erradicar la carencia alimentaria se expresan en:

i. La insuficiencia de sistemas de desarrollo tecnológico disponibles para los productores con recursos naturales de bajo rendimiento.

ii. La baja capacidad de trasferencia de tecnología a las cadenas productivas nacionales.

iii. La baja productividad para la mayoría de los productores agropecuarios.

iv. La incapacidad organizativa de las diferentes instancias públicas del sector para favorecer la interacción coordinada entre las empresas innovadoras de alta tecnología en insumos y bienes de capital y los productores agrícolas de todos tamaños.

$v$. El incremento del rezago social en el campo y de las importaciones agropecuarias.

Las condiciones anteriores se agravan porque las principales comercializadoras de granos a nivel mundial -Archer Daniels Midland (ADM), Bunge, Cargill y Louis Dreyfus- comparten una 
importante presencia en los mercados de ciertas materias primas básicas, lo que les permite controlar hasta el 90 por ciento del comercio mundial de cereales. Esta alta concentración también tiene efectos significativos en la carencia alimentaria porque las grandes empresas que controlan el mercado de materias primas influyen de manera directa en las decisiones de los productores en cuanto a qué cultivar, cómo y en qué cantidades. Con la información privilegiada que poseen pueden incidir en el mercado de futuros y manipular los precios internacionales, lo que les permite obtiene ganancias extraordinarias de las actividades interconectadas con el comercio de cereales, a saber: especulación financiera, fondos indexados, transporte y almacenamiento.

El funcionamiento del mercado internacional de granos también afecta las actividades de los pequeños productores agropecuarios e incide en el problema de la carencia alimentaria debido a que su reducida escala de producción les genera bajos niveles de producto que no les permiten integrase como abastecedores de las grandes empresas comercializadoras. Esto los coloca en desventaja frente a los acaparadores que acopian a precios muy bajos la producción de un número amplio de pequeños productores y eventualmente la venden a las grandes comercializadoras a nivel internacional (INEGI, 2019). Como los pequeños productores no tienen acceso directo a la venta de sus productos con las grandes empresas que comercian los granos alimenticios no pueden acceder a la información sobre los precios internacionales o los mercados de futuros agrícolas, lo que los induce a seguir sembrando los mismos productos sin ningún referente respecto de la composición de la producción o los acervos mundiales de granos, cereales y en general de alimentos (Murphy et al, 2012).

En ese sentido, el abandono que vive el campo y la crisis alimentaría no pueden ser solucionados con un patrón de innovación tecnológica que no considere las condiciones estructurales en que se desarrolla la producción en el campo mexicano, al contrario, sólo se profundizará la dependencia alimentaria del exterior porque los factores clave para incrementar la productividad de nuestro sector agrícola están sujetos de manera absoluta a los intereses de las grandes transnacionales, lo que impide avanzar hacia el logro de la soberanía alimentaria (FAO, 2004; 2006).

Debido a que los estándares de producción de alto rendimiento no se corresponden con las condiciones de extensión del terreno de los ejidatarios y comuneros su participación en la producción nacional desde los años cuarenta hasta la actualidad ha presentado una tendencia descendente. Asimismo, su falta de conocimientos sobre los mecanismos de comercialización estructurados por las grandes empresas provoca que los pocos ejidos capaces de integrarse al mercado en expansión lo hagan en términos administrativos y técnicos ineficientes en la medida en que las habilidades empresariales no pueden ser promovidas desde una perspectiva normativa, pues implican tomar en cuenta las condiciones de competencia reales en las que operan los productores agropecuarios. 


\section{Hacia la construcción de una política pública de soberanía alimentaria.}

De las 5.50 millones de Unidades de Producción Rural (UPR) agropecuarias o forestales, que aproximadamente existían en México en 2007, el 50\% se consideran de autoconsumo (equivalentes al $38 \%$ de la superficie), $35 \%$ en transición ( $42 \%$ de la superficie) y $15 \%$ (20\% de la superficie) con orientación comercial. Asimismo, el 73\% de las UPR agropecuarias tienen menos de 5 hectáreas. De éstas, 3.40 millones son consideradas como Unidades de Producción Pecuarias (INEGI, 2009); las cuales, representan aproximadamente 109.80 millones de ha, mismas que generan alrededor de 974 mil empleos permanentes remunerados. Según la Encuesta Nacional Agropecuaria (INEGI, 2019), el $53 \%$ de las unidades de producción destinan lo que producen al autoconsumo, $75.4 \%$ de estas unidades lo destinan al consumo familiar. De la misma forma, el $27.5 \%$ de las unidades de autoconsumo destinan parte de la producción no sólo al consumo familiar sino también para la alimentación de ganando. Además, 58\% de las unidades productivas reservan una parte de las semillas de su producción para siembras próximas. De los productores que comercializan parte de su producción, $53.1 \%$ de las unidades productivas lo venden a intermediarios, $25.1 \%$ va directo al consumidor y $1.2 \%$ a empacadoras o industria procesadora. Sólo el 3.5\% de las unidades productivas trabajan bajo contrato.

Los datos anteriores y las diferencias estructurales entre los productores agrícolas articulados, en un caso, a los mercados externos y, en otro, a un mercado interno con serios problemas de reproducción indican claramente que el patrón de desarrollo tecnológico impuesto a nivel mundial para el sector agropecuario ha mostrado su inviabilidad para los campesinos mexicanos. Esto hace indispensable que los diagnósticos para crear políticas públicas integradoras en el sector agrícola consideren cómo la interrelación entre los grandes productores en el campo, las comunidades agrarias y sistemas productivos debe responder, dadas sus diferencias, a las demandas actuales o potenciales de alimentos en el país. Según la Encuesta Ingreso- Gasto de los Hogares (INEGI, 2020) las familias más pobres tienen un gasto promedio que solo representa el 39,72 del promedio nacional. En este grupo se encuentran las familias rurales $(16,713,548)$ que destinan de sus ingresos totales el $44.63 \%$ para alimentos, su consumo de cereales representa el $26.22 \%$ del total de su gasto en alimentación, y en particular el consumo de tortillas representa dentro de ese $26.22 \%$, el $9.58 \%$ de su consumo de cereales.

El número de familias que se tienen ingresos por actividad agrícola es el $6.7 \%$ del total de hogares y menos del $0.5 \%$ de los ingresos totales registrados en el trimestre en que se levantó la Encuesta Ingreso-Gasto de los Hogares (INEGI, 2016). En relación con las familias que recibieron ingresos por actividades pecuarias, los porcentajes son muy similares, a saber $4.69 \%$ y $0.44 \%$ respectivamente. Es decir, en principio, la demanda potencial existe y se expresa como carencia 
alimentaria que hay que solventar para que, posteriormente y a mediano plazo, la economía campesina sea un componente fundamental del abasto de alimentos más allá de su aporte al autoconsumo que representa un ahorro del $25 \%$ del gasto en alimentos de la familia y que como fuente de ingreso de las familias del campo es menos significativa.

La producción agrícola campesina posee una estructura propia y responde a los factores internos y externos que la definen, desde la agro-biodiversidad que la integra hasta las diferentes formas de aprovechamiento de su producción, los cuales son en muchos sentidos una válvula de escape para el sistema, pues se convierten en productores de alimentos para una parte significativa de la población nacional por lo que deben de ser reconocidos en cualquier estrategia para favorecer el desarrollo económico y social para el sector agrícola. Considerando todo lo anterior se puede afirmar que la política o las políticas públicas que se diseñen para alcanzar la soberanía alimentaria deberían sustentarse en dos elementos fundamentales, a saber:

\section{A). La protección a las formas de producción campesinas y la promoción del uso de semillas criollas.}

En una política de apoyo a la alimentación, el Estado debe garantizar que los productores del campo tengan acceso a los recursos productivos de los que dependen para elevar su productividad. En particular debe alentar a los agricultores a que conserven y utilicen de forma sostenible los recursos filogenéticos para la alimentación y la agricultura, de ahí la necesidad de que se creen mecanismos institucionales para proveer servicios de extensión y asesoría específicos, así como apoyos para facilitar la comercialización de su producción o proporcionar un acceso directo al crédito de la banca de fomento.

En ausencia de políticas activas dirigidas a salvaguardar el desarrollo de los sistemas de semillas de los agricultores y a preservar los conocimientos y prácticas de cultivo tradicionales, dichos sistemas corren el riesgo de desaparecer como resultado de las presiones que se derivan las reglamentaciones que sobre el uso de las semillas (sistemas nacionales de certificación de semillas) y que están estructuradas para catalogar variedades comerciales protegidas. Esto conlleva de facto a la exclusión de las variedades tradicionales que por lo general no son lo suficientemente homogéneas, desde el punto de vista genético, para cumplir los requisitos de aprobación y certificación requeridos por los compradores de los cultivos, en particular para el sector de la exportación, quienes pueden exigir a sus proveedores que utilicen las semillas que garanticen la uniformidad y la estabilidad de la producción a costa de la diversidad y la variabilidad biológica (De Schutter, 2009).

En tales condiciones, el Estado debe crear políticas públicas, con diagnósticos precisos y reglamentaciones particulares para hacer compatible el fomento a la innovación en los sistemas de semillas comerciales y la conservación de los sistemas de semillas de los agricultores, garantizando 
que la innovación en ambos sistemas tenga como objetivo reducir la heterogeneidad estructural en el campo y generar beneficios económicos reales para los agricultores más pobres y marginados. Sólo gestionando la coexistencia de los dos sistemas se puede crear uno emergente que, en las circunstancias de crisis sanitaria mundial actual que perfila un problema alimentario mayúsculo, proporcione un equilibrio adecuado entre las necesidades de innovación, conservación y renovación de la diversidad de los cultivos, así como de mejora de los medios de vida de los pequeños agricultores, que en su gran mayoría todavía dependen de las semillas que conservan de sus propios cultivos y que donan, intercambian o venden de manera informal.

El concepto lineal de progreso que favorece la sustitución de las variedades de cultivos tradicionales por variedades de alto rendimiento en las áreas más productivas supone concebir la seguridad alimentaria como un problema básicamente de producción. Sin embargo, aunque las semillas mejoradas inicialmente pueden garantizar niveles más elevados de productividad por hectárea, la eliminación de la carecía alimentaria y el logro de la soberanía alimentaria seguirán siendo un desafío. No solo por los problemas vinculados a la competencia por la tierra, sino porque los que se están generando debido al cambio climático aumentarán las violaciones del derecho a la alimentación con efectos negativos directos en la accesibilidad a los alimentos y los ingresos entre la población más pobre, incluidos los pequeños agricultores. Problemas cuya solución no puede ignorar que para garantizar la seguridad alimentaria en el futuro será necesario proteger la diversidad genética de los cultivos, incluida la diversidad biológica agrícola (Schejtman, 1980, De Schutter, 2009;).

\section{B). Asegurar el derecho a alimentación adecuado y promover el desarrollo económico territorial.}

Como la inseguridad alimenticia es una dimensión básica de la vulnerabilidad, las políticas públicas de desarrollo agrícola deberán incorporar en sus diseños mejores formas de intervención pública y estrategias de implementación donde los gobiernos y los proveedores institucionales de apoyos directos al campo tengan como referente fundamental de sus actividades el logro de la seguridad alimentaria. En este caso las evaluaciones participativas y la creación de redes para contender con la pobreza son fundamentales en cualquier esquema de política pública que pretenda reducir o eliminar la carencia alimentaria ya que el hambre y la falta de una dieta adecuada constituyen no sólo una dimensión clara de la privación, sino que contribuyen a perpetuar la desigualdad y a reducir de oportunidades de desarrollo en los núcleos poblacionales más pobres.

En esos términos, el análisis del entorno territorial de las políticas públicas agrícolas debe incorporar una idea clara de que la producción campesina tiene una racionalidad sustantiva y técnica que produce y reproduce los vínculos sociales de la colectividad campesina y las bases materiales del desarrollo sustentable a través de medios y técnicas que orientan sus procesos productivos. Por lo 
tanto, tiene que considerarse la dimensionalidad de reproducción social de la producción agrícola, la cual se manifiesta en dos esferas: una, en la que los cultivos que producen son medios de vida para los campesinos que los cosechan y formas de paliar la excesiva concentración del ingreso y la falta de empleo; y, otra, en la que la producción que comercializan les permite sortear los cambios de precios en el mercado capitalista de los cultivos a los que se dedican (Deparment for International Development, 1999).

En tal sentido, la formulación de políticas públicas para el sector agrícola deberá considerar las diferentes cadenas productivas y su impacto para la economía territorial, diferenciando las cadenas de consumo local respecto al territorio estudiado, cuyo destino principal es el consumidor nacional, y las cadenas globales que se relacionan con productos para los mercados internacionales. El objetivo es integrar con una visión multidimensional y de prospectiva de desarrollo agrícola acciones de gestión que logren articular a los pequeños productores y sus organizaciones con otros eslabones, tales como proveedores de insumos y servicios, procesadores (tanto grandes compañías como pequeñas y medianas empresas), distribuidores (tradicionales y/o modernos) y consumidores.

Por lo tanto, el diseño, implementación y la evaluación de las políticas necesarias para el sector agrícola deberán incorporar intervenciones que favorezcan un desarrollo más articulado de las cadenas productivas desde los territorios porque esas cadenas tienen un potencial para generar ingresos y empleo mucho mayor del que normalmente se estima. Esto es importante porque las dinámicas territoriales que desplazan la producción de los granos básicos ponen en peligro la seguridad alimentaria y no son beneficiosas para la economía local. Consecuentemente, en la formulación de políticas para favorecer el desarrollo del entorno territorial se debe incorporar el acceso al mercado (la gestión postcosecha, el procesamiento y la comercialización de productos), el asesoramiento y suministro de insumos, la formación y asistencia técnica, la provisión de tecnología y desarrollo de productos y de mecanismos de financiación alternativos (Gottret, 2011; Martinetti, 2014). Sin omitir que el logro de la seguridad y soberanía alimentaria demanda políticas públicas que recuperen y aumenten de manera sostenible, la capacidad productiva en granos básicos.

Todo lo anterior será insuficiente sí en el marco de una política de desarrollo rural integral no se considera la importancia de la agricultura familiar y las necesidades de los pequeños productores, las pequeñas y medianas empresas, esto en contrapartida a lo que históricamente ha sucedido en el país donde los mayores beneficios y estímulos has sido para subsidiar a los grandes productores nacionales y transnacionales. 


\section{$\rightarrow$ 4. Conclusiones.}

El campo mexicano y particularmente los medianos y pequeños productores enfrentan un conjunto de problemáticas caracterizadas por la falta de acceso a tecnología de punta, la escasez de oferta de agro-insumos adecuados al tipo de suelo que tienen, altos precios de los energéticos y una limitada capacidad económica para acceder a los alimentos que requieren. Situación que se agrava por el uso ineficiente de recursos hídricos frente al aumento de las sequias y la disminución en la calidad del agua. Adicionalmente, como la capacitación y la asistencia técnica son insuficientes e inadecuadas, se requieren apoyos técnicos e información para insertar a los pequeños productores en estrategias que fortalezcan y articulen los diferentes sistemas-producto. Esos fenómenos provocan que no sólo se rezaguen en términos de productividad frente al segmento más dinámico del sector agrícola, sino que se vean sometidos a procesos de marginación social que se muestran claramente en la existencia de una condición estructural de carencia alimentaria, pues sus ingresos son muy reducidos.

Cuando se integran a las cadenas de comercialización nacionales no reciben las derramas económicas justas por la venta de sus productos pues son víctimas de acaparadores. Además, su oferta agrícola es estacionaria y aleatoria ya que la productividad de la superficie de temporal en que siembran y cosechan se asocia al nivel de precipitación pluvial y a condiciones meteorológicas favorables para la producción, mientras que su potencial para incorporarse a las cadenas de valor está desintegrado por las precarias condiciones de producción que tienen. Para este segmento de productores agrícolas, los instrumentos de la política pública en el sector son crecientemente indirectos y multisectoriales. Por lo que hace falta su redireccionamiento hacia actividades productivas y de mercadeo en particular en los casos en los que se pueda favorecer a los productores en las zonas rurales pobres que enfrentan una competencia desigual que los margina y permite su sobre sobrexplotación.

En esos términos, las políticas públicas para el sector agrícola tendrían que partir de reconocer, en el contexto de una crisis sanitaria y económica sin precedentes desde los años treinta del siglo pasado, que tanto el patrón tecnológico de punta existente en la agricultura de exportación como la modernización excluyente que históricamente han prevalecido en el campo mexicano afectan a la mayor parte de los campesinos y los condenan a la pobreza y a la carencia alimentaria.

En ese marco, las políticas públicas para el sector agrícola tendrían que incorporar aspectos de desarrollo tecnológico, organización de la producción y cuidado al medio ambiente. Es decir, mejorar la productividad del campo desde una perspectiva de planificación y gestión implica que las políticas públicas del sector partan de un diagnóstico integrador para diseñar acciones encaminadas a acoplar los sistemas de semillas comerciales y los sistemas de semillas de los agricultores, lo que pasa 
por fomentar la participación a nivel local de todos los interesados (desde los productores hasta los consumidores). Esto permitiría desarrollar las mejoras requeridas para reconstruir el sistema alimentario nacional y, a partir de ello, definir estrategias de bienestar social capaces de contribuir a la creación de empleos estables y sostenibles que redundarían en ingresos suficientes y condiciones de vida y de trabajo decentes para todos los involucrados en la producción agrícola.

En ese contexto, el estado tendría que poner en práctica, como parte de las políticas públicas para el sector agrícola, estrategias de intervención para la creación de redes de agricultores pequeños y medianos con toda la asesoría técnica y financiera que le permita potenciar su producción para logar su paulatina articulación a los mercados de alimentos internacionales con condiciones favorable y competitivas.

Todo lo anterior no estaría completo si entre los ejes orientadores de las políticas públicas para el sector agrícola no se considera que el aumento de la capacidad productiva debe asociarse en todo momento a la base de los recursos naturales como un todo y a la capacidad regenerativa de los recursos renovables, sin romper los ciclos ecológicos básicos y los equilibrios naturales, ni destruir las características socioculturales de las comunidades rurales. Con lo que se logaría, por una parte, garantizar que los requerimientos nutricionales básicos de las generaciones presentes y futuras (dieta sostenible) sean atendidos cualitativa y cuantitativamente mediante el desarrollo de cadenas productivas locales y, por otra, reducir la vulnerabilidad del sector agrícola frente a factores naturales y socioeconómicos adversos derivados de la actual emergencia sanitaria y económica. 


\section{Bibliografía y referencias documentales}

Aboites, Gilberto y Félix, Gustavo (2011). Centroamérica uso de semillas genéticamente e incremento del ingreso de los agricultores. CEPAL, Naciones Unidas Sede Subregional de México.

Bartra, Roger (2007). La medición y monitoreo de la inseguridad alimentaria: consideraciones para el desarrollo de un indicador." Recuperado desde http://aprendeenlinea.udea.edu.co/revistas/index.php/nutricion/article/view/338838/20793876

Bouquet, Emmanuelle (1996). "La tierra ejidal en México: mercancía u objeto social”, en Estudios Agrarios, México, pp. 79.-104.

Bratspies, Rebecca (2017). "Owning all the seeds: consolidation and control in Agbiotech", en Enviromental Law, Vol. 47, Portland, Lewis \& Clark Law School, September, pp. 583-608

Cámara de Diputados. (2019). Resultados de la Medición de la Pobreza Multidimensional en Materia Alimentaria 2018. Centro de Estudios para el Desarrollo Rural Sustentable y la Soberanía Alimentaria, LXIV Legislatura, México.

CECCAM (2008). Las semillas del hambre: ilegalizar la memoria campesina, Red en Defensa del Maíz. Recuperado desde: http://ceccam.org/sites/default/files/semillas\%20texto\%20foll2011.pdf

CONEVAL (2014). Hallazgos del estudio. El acceso a los alimentos en los hogares, 2013-2014.

CONEVAL (2018a). Anexo Estadístico de la Medición de la pobreza 2008-2018. Recuperado desde: https://www.coneval.org.mx/Medicion/MP/Paginas/AE_pobreza_2018.aspx

CONEVAL (2018b). Evaluación de la Política de Desarrollo social. Recuperado desde: https://www.coneval.org.mx/Evaluacion/IEPSM/IEPSM/Paginas/IEPDS-2018.aspx

CONEVAL (2020). Medición de la pobreza 2020. Recuperado desde: https://www.coneval.org.mx/Medicion/MP/Paginas/Pobreza_2020.aspx

Conroyd, Héctor, Ramos, Johanna., Tang, Li y Ramírez-Goldin, Ana (2014). Proyectos de regularización y administración de tierras: implicaciones económicas de la regularización y la mejora en la administración de tierras. Evaluación Comparativa, Anexo Técnico I, BID.

Correa, Carlos (2015). La protección de las obtenciones vegetales para los países en desarrollo. Una Herramienta para el diseño sui generis de protección de las obtenciones vegetales. Una alternativa al acta de 1991 del Convenio de la UPOV. APBREBES, Third World Network. Recuperado desde: https://www.apbrebes.org/files/seeds/ToolSpanishcomplete.pdf

Deininger, Klaus (2003). Políticas de tierras para el crecimiento y la reducción de la pobreza. A World Bank Policy Research Report. Banco Mundial-Alfaomega. Washington, D.C.

Department for International Development (1999). Sustainable Livelihoods Guidance Sheets. Recuperado desde: https://www.ennonline.net/attachments/871/dfid-sustainable-livelihoods-guidance-sheetsection1.pdf

De Schutter, Oliver (2009). Las políticas de semillas y el derecho a la alimentación: mejora de la biodiversidad de la agricultura y fomento de la innovación, Asamblea General de las Naciones Unidas, 23 de julio de 2009, Recuperado de: http://www.srfood.org/images/stories/pdf/officialreports/20091021_reportga64_seed-policies-and-the-right-to-food_es.pdf

De Schutter, Oliver (2010), The right to food Promotion and protection of human rights: human rights questions including alternative approaches for improving the effective enjoyment of human rights and fundamental freedoms, Asamblea General de las Naciones Unidas, 11 de Agosto 2010. Recuperado de: http://www.srfood.org/images/stories/pdf/officialreports/20101021_access-to-land-report_en.pdf

Erard. Pascal, Jorand. Maureen, Laurent, Morgan y Mainenti. Carline (2017), El Derecho a Las Semillas: Un derecho esencial para lo-a-s campesino- $a-s$, Paris, Coordinación SUD. Recuperado de: https://www.grain.org/es/article/5738-el-derecho-a-las-semillas-un-derecho-esencial-para-los-ascampesino-as 
ETC Group. (2013), Putting the Cartel before the Horse ...and Farm, Seeds, Soil, Peasants etc. Who Will Control Agricultural Inputs? The State of Corporate Concetration, 2013? Communique, No 111, Ottawa, september.

Foro Mundial sobre Soberanía Alimentaria (2001). La Habana, Cuba, septiembre.

FAO. (1996). Cumbre mundial sobre alimentación, Roma, Italia, 13-17 de noviembre. Recuperado desde https://www.fao.org/3/x2051s/x2051s00.htm

FAO (2004), Política de desarrollo agrícola: conceptos y experiencias. Recuperado de: http://www.fao.org/docrep/007/y5673s/y5673s09.htm\#TopOfPage

FAO (2006), Seguridad alimentaria. Informe de politicas. Recuperado de: $\mathrm{ftp} / / / \mathrm{ftp}$.fao.org/es/esa/policybriefs/pb_02_es.pdf

FAO. (2018). México Rural del Siglo XXI, México.

Gallardo, Rubén (2003). Reforma constitucional de 1992. El surgimiento del nuevo Derecho Agrario mexicano, Conferencia en el Diplomado en Derecho Agrario en México, SEDATU-Procuraduría agraria. Recuperado de: http://www.pa.gob.mx/publica/rev_61/Reforma-constitucional-1992.pdf

Giraldo. Omar (2015). “Agroextractivismo y Acaparamiento de Tierras en América Latina. Una visión desde la Ecología Política”, en Revista Mexicana de Sociología, Vol.77, No.4, pp- 637-662.

Gottret, María (2011), "Desarrollando un portafolio de cadenas de valor para el desarrollo territorial: La articulación del enfoque de cadenas de valor con el enfoque de medios de vida", en Demenus W y Coello PC (coordinador), Cadenas Productivas y Desarrollo Económico Rural en Latinoamérica, Quito, ONCOPE.

Henderson, Heath., Corral, Leonardo, Simming, Eric and Winters, Paul (2014). Land accumulation dynamics in developing country agriculture, Working paper Series No. IDB-WP-519. Office of Strategic Planning and Development Effectiveness, BID.

Herrera. Francisco. (2013). "Enfoques y política de desarrollo rural en México. Una revisión de la construcción institucional”, en Gestión y Política Pública. VOLUMEN XXII. NÚM. 1. pp. 131-159

INEGI (2009), Censo Agropecuario (2007), VIII Censo Agrícola, Ganadero y Forestal, Recuperado de: http://www.inegi.org. $m x$

INEGI (2012). Encuesta Nacional Agropecuaria. Recuperado desde: https:/www.inegi.org.mx/contenidos/programas/ena/2012/doc/ena2012_mini.pdf

INEGI (2016). Encuesta Nacional de Ingresos y Gastos de los Hogares. ENIGH 2016. Tabulados básicos. (2017), Recuperado desde: https:/www.inegi.org.mx/programas/enigh/nc/2016/

INEGI (2017). Encuesta Nacional Agropecuaria. Recuperado desde: https://www.inegi.org.mx/contenidos/programas/ena/2017/doc/mini_ena17.pdf

INEGI (2019). Encuesta Nacional Agropecuaria. Recuperado desde: https://www.inegi.org.mx/contenidos/programas/ena/2019/doc/rrdp_ena2019.pdf

INEGI (2020). Encuesta Nacional de Ingresos y Gastos de los Hogares. ENIGH. Recuperado desde: https:/www.inegi.org.mx/programas/enigh/nc/2020/\#Documentacion

Jaffé, Walter (1993). Política Tecnológica y Competitividad Agrícola en América Latina y el Caribe. IICCA, San José.

Kato, Luis (2005), "Impactos Sociales de la Crisis Agroalimentaria soberanía alimentaria y el uso de transgénicos para satisfacer las necesidades alimenticias de la población” en: Ana Alicia Solís et al. Soberanía Nacional Crisis Políticas y Movimientos Sociales, México, ITACA.

Kay, Cristobal (1995). "El desarrollo excluyente y desigual en la América Latina rural”., en Revista Nueva Sociedad, No. 137. pp.60-81

Lavarello, Pablo y Goldstein, Evelyn (2011). “Dinámicas heterogéneas en la industria de maquinaria. agrícola argentina.”, en Problemas del Desarrollo, México 166 (42), México, UNAM-IIEc, julio-septiembre.

Leyva, Arisbel (2012). “Entrevista a Armando Bartra Vergés”, en Revista Chapingo, pp.9-32. 
Martinetti, Ana (2014), "Los mercados solidarios desde la economía social y solidaria. La experiencia de AFIH", en III Jornadas Nacionales sobre estudios regionales y mercados de trabajo, Facultad de Cs. Económicas y Unidad de Investigación en Comunicación, Cultura y Sociedad de la Facultad de Humanidades y Cs. Sociales y Red SIMEL, San Salvador de Jujuy, Universidad Nacional de Jujuy.

Murphy, Shopia, Burch, David, y Clapp, Jennifer (2012), El Lado Oscuro Del Cereal: Las mayores comercializadoras de cereal del mundo y la agricultura mundial, Oxford, Reino Unido, Informes de Investigación, OXFAM.

OECD. (2018). Agricultural Policy Monitoring and Evaluation 2018, OECD Publishing, Paris. Recuperado en: https://doi.org/10.1787/agr_pol-2018-en.

Pérez, Juan. y Mckinlay. Horacio (2015). “Existe aún la propiedad social agraria en México?”, en POLIS, vol. 11, núm. 1, pp. 45-82.

RAN (2017). Nota Técnica sobre la propiedad Social. Gobierno de México.

RAE (1992). Diccionario de la Lengua Española, Real Academia Española, España, Mateu-Cromo.

SAGARPA. Sistema de Información Agroalimentaria y Pesquera (SIAP). Estadísticas de la Producción Agrícola. Recuperado desde: http://infosiap.siap.gob.mx/gobmx/datosAbiertos_a.php

Schejtman, Alexander (1980), "Economía campesina: lógica interna, articulación y persistencia", en Revista Cepal, Santiago, agosto.

SIE (2019). Banco de México, Balanza de Pagos. Saldos Agropecuarios y Agroindustrial. Disponible en: https://www.banxico.org.mx/SieInternet/consultarDirectorioInternetAction.do?sector=1\&accion=con sultarCuadroAnalitico\&idCuadro $=$ CA187\&locale $=$ es

Torres-Mazuera, Gabriela (2019). Tierras Ejidales ¿Mercancía o Territorios indígenas? Intermediación legal y nuevas interpretaciones disonantes de la legislación agraria en el México contemporáneo. Caravelle en Línea. 112 Dossier - Justice et infra-justice dans le Mexique indépendant, pp. 95-108, Disponible en: https://journals.openedition.org/caravelle/5605

Williams, Gary (2007). "El cambio técnico y la agricultura: La experiencia de los Estados Unidos e implicaciones para México", Revista Mexicana de Agronegocios, vol. Xl, núm. 20, enero-junio, pp. 209-220. 


\section{Números anteriores}

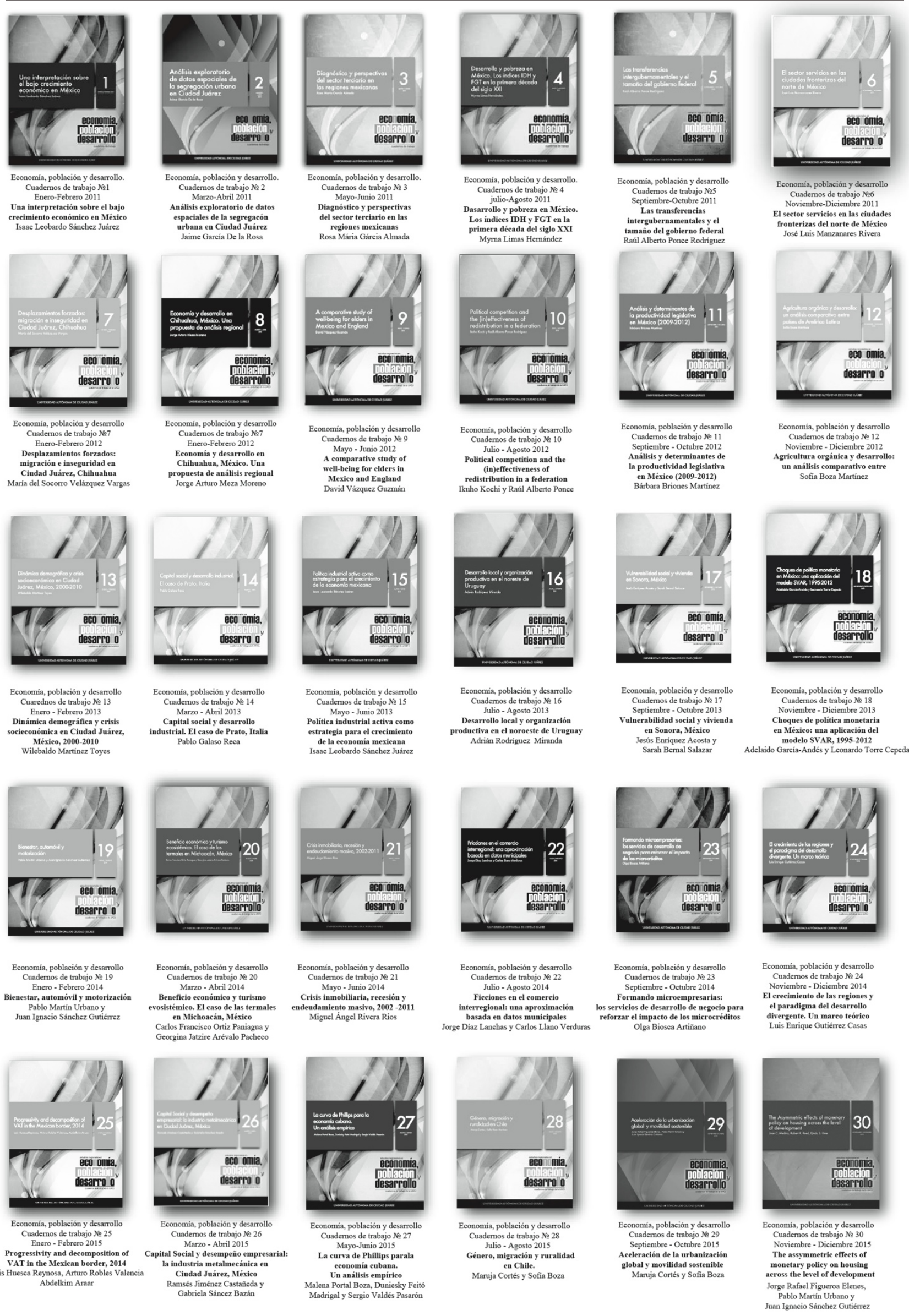



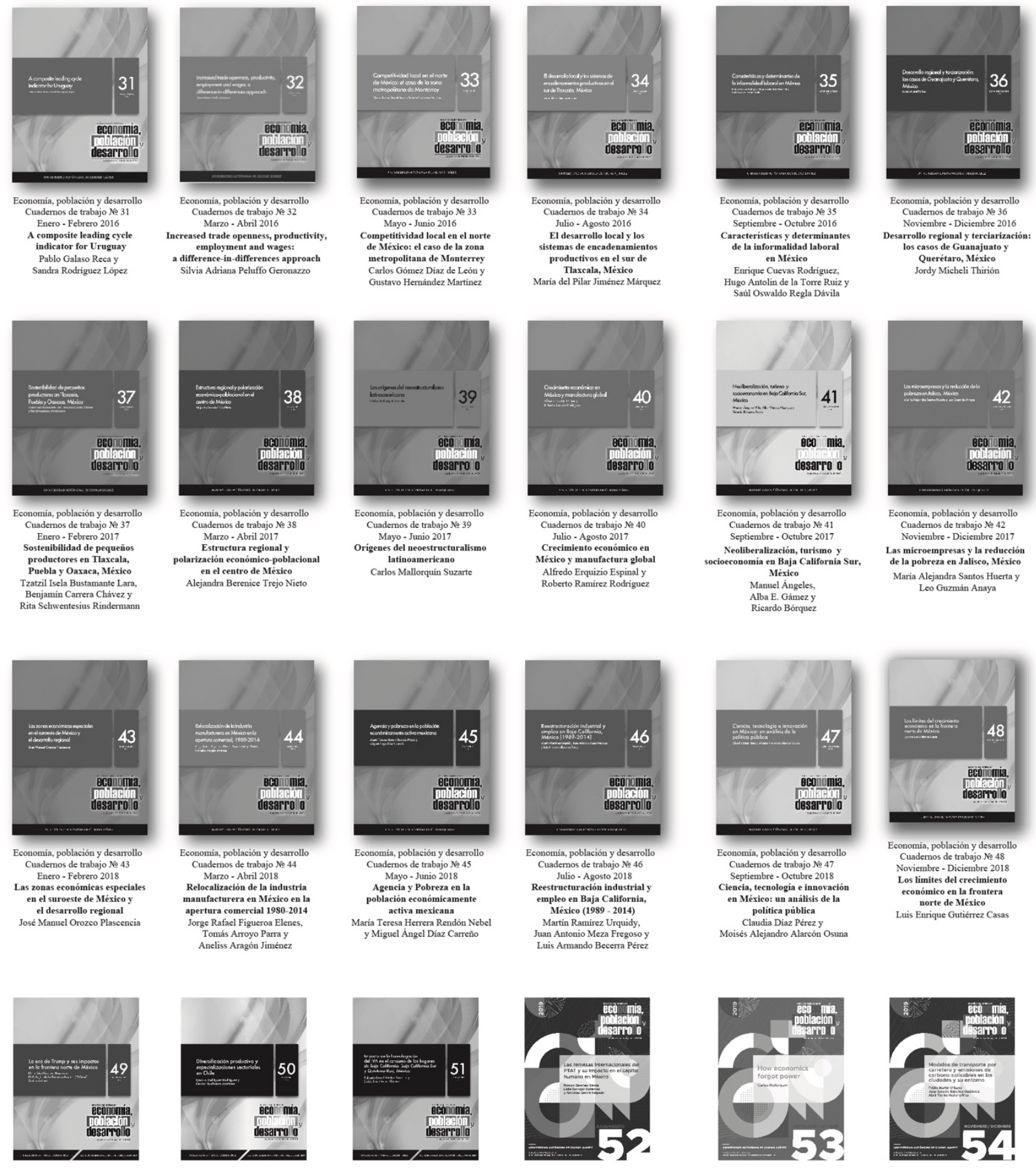

Economia, población y desararollo
Cuadernos de trabajo No 49
Enero - Febrero 2019

La era de Trump y sus impactos
en la frontera norte de Mérico

Dirección General doroeste

Varios autores

Economia, población y desarrollo
Cuadernos de trabajo № 50 Marzo - Abril 2019

Diversificación productiva y
especializaciones sectoriales en Chile

Economia, población y desarrollo
Cuadernos de trabajo № 51 Mayo - Junio 2019
pacto de la homologacio

Impacto de la homologación del IVA en el consumo de los hogares de
Baja Califoria, Baja Califoria Sur Ignacio Rodriguez Rodriguez
Paulina Sanhueza Martinez
Economiá, población y desarrollo
Cuadernos de trabaje No 52 Julio - Agosto 2019
Las remesas internacionales
del PTAT y su impacto en
el PTAT y su impacto
el capital humano
Romin Sánchez Dávila
Lidia Carvajal Gutiérrez y
Oswaldo Garcia Salgado

Rolando Israel Valdez Ramirez y
Emilio Hermaindez Gómez
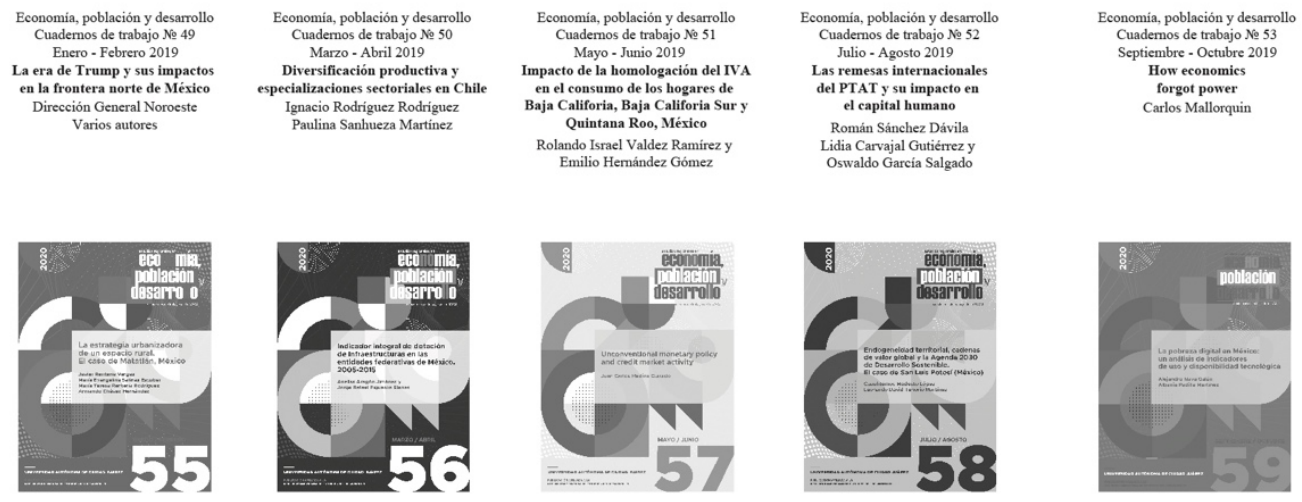

Economia, población y desarrollo
Cuadernos de trabajo No 54 Noviembre - Diciembre 2019
Modelos de transporte por carretera Modelos de transporte por carretera y
emisiones de carbono aplicables en las
cindades $y$ su entorno ciudades y su entorno Juan Ignacio Sánchez Gutiérre y Abril Yuriko Herrera Ríos

Economia, población y desarrollo Enero - Febrero 2020 La estrategia urbanizadora
de un espacio rural. de un espacio rural.
El caso de Matatlán, México Javier Renteria Vargas, Maria Evangelina Salinas Escobar,
Maria Teresa Renteria Rodriguez Armando Chávez Hernánde

Economia, población y desarrollo
Cuadermos de trabajo No 56 Cuademos de trabajo
Marzo - Abril 2020 Indicador integral de dotación de
infraestructuras en las entidades Tederativas a
2005-2015 Aneliss Aragón Jiménez y
Jorge Rafael Figueroa Elenes

\section{Economia, poblecín y desa uadernos de trabajo № 57} and creditmarket activity Juan Carlos Medina Guirado
Economia, población y desarrollo Julio - Agosto 2020 Endogeneidad territorial, cadenas de valor global y la
Agenda 2030 de Desarrollo Sostenible. Agenda 2030 de Desarrollo Sostenible
El caso de San Luis Potosi (México) Cuauhtémoc Modesto López y
Leonardo David Tenorio Martinez
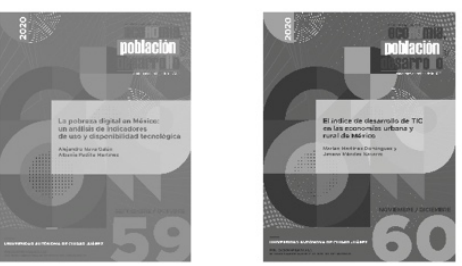

Economia, población y desarrollo Septiembre - Octubre 2020 La pobreza digital en México: disponibilidad tecnológica Alejandro Nava Galán y
Economia, población y desarrollo os de trabajo NoO $^{2}$ El indice de desarrollo de TIC en las economias
urbana y rural de México Marlen Martinez Domingue 


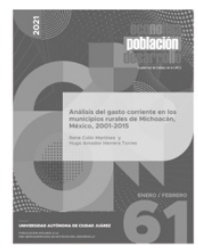

Economiá, población y desarrollo
Cuadermos de trabajo Enero - Febrero 2021 Análisis del gasto corriente en los
nunicipios rurales de Michoacin, René Colin Martinez y
Hugo Amador Herrera Torres

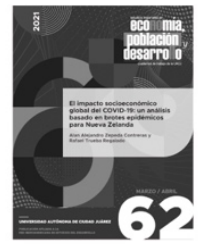

Economia, población y desarrollo
Cuadermos de trabajo

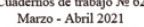

El impacto socioeconomico
global del CoVID-19:

un análisis basado en
rotes epidémicos para
Nueva Zelanda

Alan Alejandro Zepeda Contrer
Rafael Trueba Regalado

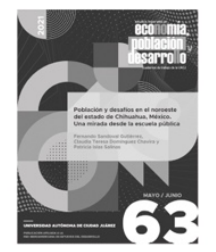

Economia, población y desarrollo
Cuademos de trabajo № 63

Poblacion y desafios en el noroeste
del estadood de Chituananua, Mexico.

escuela pública
and

Femando Sandoval Gutiérez,
Claudia Teresa Dominguez Chavira y Patricia Islas Salinas
y

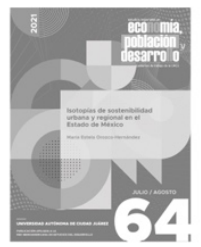

Economia, población y desaralllo
Cuademos de trabajio

Cuademos de trabajo No 640
Julio - Agosto 2021 $\begin{gathered}\text { Isotopias de sostenibilidad } \\ \text { urbana y regional } \\ \text { en el Estado de Mérico }\end{gathered}$
. Maria Estela Orozeo-Hemandez
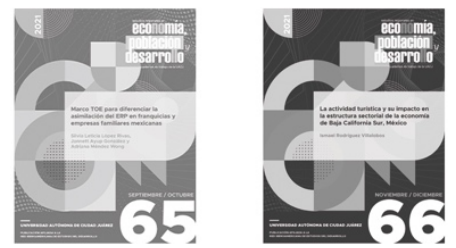

Economia, población y desarrollo Marco TOE para diferencia asimilación de ERP en franquarisias
y empresas familiares mexicanas Silvia Leticia López Rivas
Jannet Ayur Gonzalez y
Economia, población y desarrollo

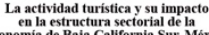
Ismael Rodriguez Villalobos 


\section{Para el documento general:}

Tipo de letra: Times New Roman.

Tamaño: 11 puntos.

Interlineado: 1.5 espacios.

Títulos y subtítulos:

El texto principal en 11 puntos. Títulos 12 puntos (en resaltado). Subtítulos 11 puntos. Cada título y subtítulo deberá numerarse bajo el siguiente orden: 1, 1.1, 2, 2.1, 2.2...

La extensión máxima de los cuadernos de trabajo será de 40 cuartillas.

La primera vez que se emplee una sigla en el texto se especificará primero su equivalencia completa y después la sigla.

\section{Hoja de presentación:}

Título:

14 puntos, centrado, resaltado.

Nombre de autor(es):

12 puntos

Resumen y abstract:

Debe incluir resumen en español y abstract (diez puntos), no mayor a 250 palabras

Palabras clave:

Incluir entre tres y cinco palabras clave, en español e inglés

Referencia del autor o autores:

Institución de adscripción, grado académico y líneas-grupos de investigación que desarrolla y a los que pertenece.

\section{Sistema de referencia de citas:}

Harvard-APA

Las citas bibliográficas en el texto deberán incluir entre paréntesis sólo el apellido del autor, la fecha de publicación y el número de página; por ejemplo: (Quilodrán, 2001: 33).

\section{Notación en sección de bibliografía y fuentes de información:}

Se deberá incluir al final del texto. Toda referencia deberá estar mencionada en el texto o notas de pie de página.

Cada referencia iniciará con el primer apellido o los apellidos, luego el nombre del autor, y después, entre paréntesis, el año de publicación seguido de un punto. Ejemplos:

Se deberá incluir al final del texto. Toda referencia deberá estar mencionada en el texto o notas de pie de página.

Cada referencia iniciará con el primer apellido o los apellidos, luego el nombre del autor, y después, entre paréntesis, el año de publicación seguido de un punto. Ejemplos: 
Artículo:

Ros, Jaime (2008). "La desaceleración del crecimiento económico en México desde 1982", en Trimestre Económico, vol. 75, núm. 299, pp. 537-560.

Libro:

Villarreal, René (2005). Industrialización, competitividad y desequilibrio externo en México.

Un enfoque macroindustrial y financiero (1929-2010), México, Fondo de Cultura Económica.

Capítulo de libro:

Castillo, Manuel Ángel (2003). "La política de inmigración en México: un breve recuento", en Manuel Ángel Castillo, Alfredo Lattes y Jorge Santibáñez (coords.), Migración y fronteras, Tijuana,

El Colegio de la Frontera Norte / Asociación Latinoamericana de Sociología / El Colegio de México, pp. 425-451.

\section{Notas de pie de página:}

Se utilizarán para hacer indicaciones complementarias, aclaraciones o ampliación de una explicación. La nota de pie de página en Times New Roman, 10 puntos.

\section{Tipología de imágenes dentro del texto:}

Cuadro

Gráfica

Diagrama

Mapa

Figura

Todas las imágenes deben ser numeradas y mencionadas dentro del texto. A toda imagen debe incluirse la fuente.

Las indicaciones de la imagen: tipo y número de imagen, título de imagen y fuente se escriben en 10 puntos. En el texto poner como imagen los mapas, figuras, gráficas y diagramas -con el ánimo de no perder el formato realizado por el autor.

\section{Ecuaciones y fórmulas:}

Si se utilizan ecuaciones o fórmulas deberá utilizarse el editor de ecuaciones de Word y numerarse.

\section{Envío de trabajos}

Los trabajos deben ser enviados a la dirección de correo: lgtz@uacj.mx. Con el Dr. Luis Enrique Gutiérrez Casas, editor de esta publicación.

La aceptación de cada colaboración dependerá de la evaluación de dos dictaminadores especialistas en la materia que se conservarán en el anonimato, al igual que el autor (autores) para efectos de la misma. 


\section{For General Document:}

Font type: Times New Roman.

Size: font size 11.

Paragraph: 1.5 line spacing.

Titles and subtitles: Main text font size 11. Titles font size 12 (Bold). Subtitles font size 11.

Each title and subtitle should be numbered in the following order: 1, 1.1, 2, 2.1, 2.2...

The maximum length of the workbooks will be 40 pages.

The first time an abbreviation is used in the text will be specified first complete equivalence and then stands.

\section{Front cover:}

Title:

Font size 14, centered, Bold.

Author name(s):

Font size 12.

Abstract:

It should include abstract in Spanish and abstract (font size 10), no more than 250 words.

Keywords:

Include three to five keywords, in Spanish and English.

Reference of author:

Institution of affiliation, academic degree and line-developed by research groups and belonging.

\section{Bibliographical appointment system:}

Harvard-APA

Citations in the text should include between parentheses only the author's name, publication date and page number, for example:

(Quilodrán, 2001: 33).

\section{Notation about Bibliography section and Information fonts:}

Should be included at the end of the text. All references must be mentioned in the text or footnotes page.

Each reference starts with the first name or last name, then the name of the author, and then, in parentheses, the year of publication followed by a period. Examples:

Article:

Ros, Jaime (2008). "La desaceleración del crecimiento económico en México desde 1982”, en Trimestre Económico, vol. 75, núm. 299, pp. 537-560. 


\section{Editorial Guidelines}

Book:

Villarreal, René (2005). Industrialización, competitividad y desequilibrio externo en México. Un enfoque macroindustrial y financiero (1929-2010), México, Fondo de Cultura Económica.

Book chapter:

Castillo, Manuel Ángel (2003). "La política de inmigración en México: un breve recuento", en Manuel Ángel Castillo, Alfredo Lattes y Jorge Santibáñez (coords.), Migración y fronteras, Tijuana, El Colegio de la Frontera Norte / Asociación Latinoamericana de Sociología / El Colegio de México, pp. 425-451.

\section{Footnotes:}

Must be used to make additional indications, clarification or expansion of an explanation. The footnotes must be in Times New Roman, font size 10 .

\section{Image typology inside text:}

Picture

Graph

Diagram

Map

Figure

All images must be numbered and mentioned in the text, should include the source image. The indications of the image: type and number of image, image title and source are written in 10 font size. In the text set as image maps, figures, graphs and charts-with the intention of not losing the formatting by the author.

\section{Equations and Formulae:}

When using equations or formulas should be used in Microsoft Word equation editor and numbered.

\section{Paper sending}

Entries must be sent to the email address: lgtz@uacj.mx. With Dr. Luis Enrique Gutiérrez Casas, editor of this publication.

Acceptance of each collaboration will depend on the evaluation of two examiners skilled in the art to be kept anonymous, like the author(s) for the same purposes. 
Publicación afiliada a la

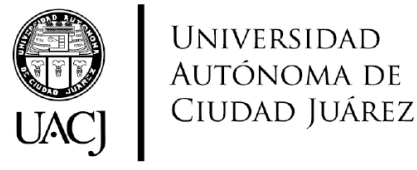

Red
RIED

Esta obra se editó y terminó de imprimir en Ciudad Juárez, Chihuahua, México 
